\title{
Factors influencing patients' preferences for their treating physician
}

KhalidS.Alraddadi, MBBS, FayzahAl-Adwani, ABFM,ZiadA. Taher, MBBS, MubarkAl-Mansour, FRCPC, MuhammadKhan, MME.

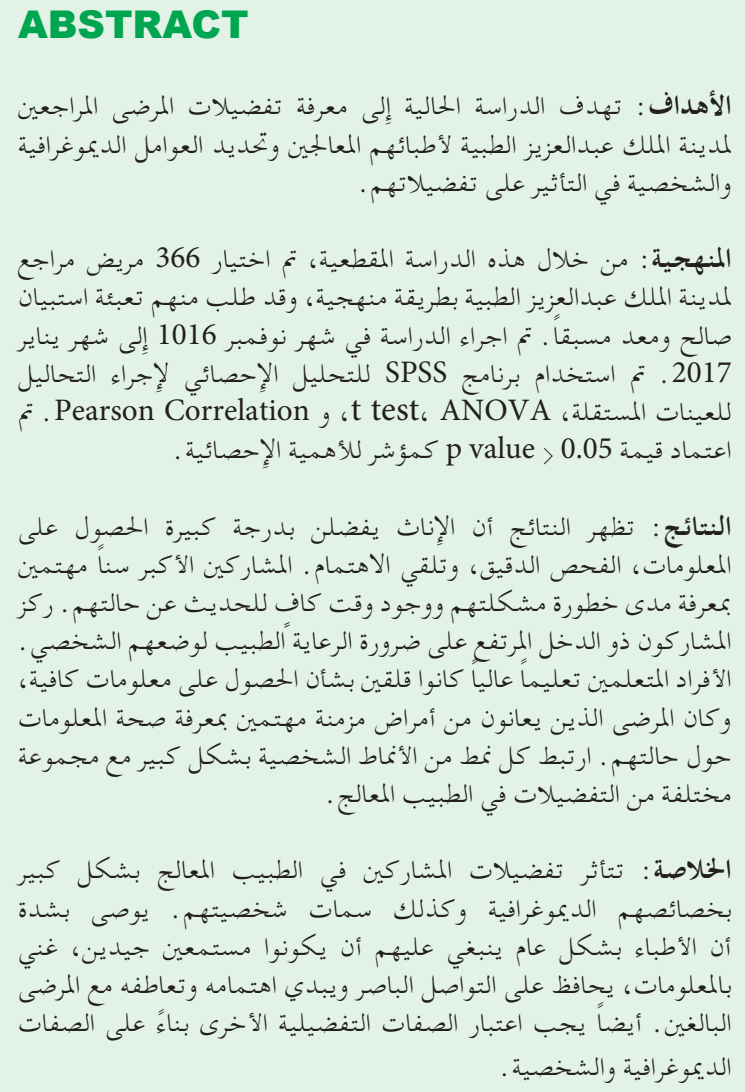

Objectives: To explore preferences of the patients attending King Abdulaziz Medical City (KAMC), Jeddah, Saudi Arabia, in their treating physicians and to determine demographic and personal factors influencing their preferences.

Methods: Through a cross sectional design, 366 patients attending KAMC were systematically selected, and were requested to a pre-designed valid questionnaire. The study conducted between November 2017 and January 2018. The Statistical Package for Social Sciences was used for statistical analysis which included independent sample t-test, ANOVA and Pearson correlation. A $p$-value $<0.05$ was considered significant.
Results: The study showed that females were significantly more preferring to get information, careful examination and receiving attention. Older respondents were interested in finding out how serious is their problem and having enough time for talking about their condition. Higher income respondents focused on necessity of physician caring for their personal situation. Highly educated individuals were concerned about getting enough information, and patients with chronic diseases were much interested by the truth of their condition. Each dimension of the personality traits was significantly correlated with different package of preferences in their treating physician.

Conclusion: Respondents' preferences in their treating physician are significantly influenced by their demographic characteristics as well as their personality traits. It is highly recommended that physicians, generally, should be attentive listener, informative while discussion, maintaining eye contact and showing interest and empathy for adult middle-aged patient. Also, to consider other preferable features based on patients' demographics and personalities.

Keywords: patients' preferences, doctor-patient relationship, effective health care service

Saudi Med J 2020; Vol. 41 (8): 866-873 doi: 10.15537/smj.2020.8.25192

From the Department of Family Medicine (Alraddadi, Al-Adwani); from the Department of Oncology (Al-Mansour), King Abdulaziz Medical City, from the College of Medicine (Taher); and from the Medical Education Unit (Khan), King Saud bin Abdulaziz University for Health Sciences, Jeddah, Kingdom of Saudi Arabia.

Received 7th February 2020. Accepted 24th June 2020.

Address correspondence and reprint request to: Dr. Khalid S. Alraddadi, Department of Family Medicine, King Abdulaziz Medical City, Jeddah, Kingdom of Saudi Arabia. E-mail: dkresearch18@gmail.com ORCID ID: https://orcid.org/0000-0002-0639-9927 
$\mathrm{T}$ he interaction between patients and their treating physician is considered as an important element in achieving better therapeutic outcomes. ${ }^{1}$ Good doctorpatient communication relieves patient worries and anxiety, and creates trustful relationship, which are important for giving proper consultation and counseling and achieving optimal prognosis. ${ }^{2,3}$ A greater number of health related problems and issues can be raised and discussed during consultations when patients have a deeper relationship with their treating physicians; that may be associated with significant benefits for both the patients and physicians with ultimate effective health care services. ${ }^{4,5}$

A considerable number of studies concerned with examining the impact of the patient-doctor relationship on various outcomes, using different measures, revealed positive outcomes in many settings, for example diabetic patients, patients with heart failure, and elderly patients. ${ }^{6-8}$ Moreover, better patient-doctor relationship had been documented to have positive impact on patient satisfaction, as well as reducing rates of avoidable admissions, duplication of dispensed medications and lowering overall cost of health care services. ${ }^{9-11}$

In the Kingdom of Saudi Arabia (KSA), the doctor-patient relationship is compromised by many factors including mixed ethnicity of the work force in the health service and the expatriate community, with a vast diversity of languages, and different health traditions and beliefs. ${ }^{12}$ Despite of its importance, little is known on the factors affecting the preferences of the Saudi patients for characteristics of their treating physicians in the primary health care centers.

Therefore, the current study aims at exploring these factors in an attempt to maximize doctor-patient relationship in KSA. Specifically, this study aims to determine the personal characteristics of the physicians preferred by the patients attending King Abdulaziz Medical City (KAMC), Jeddah, KSA, and to identify factors influencing preferences of the patients for their treating physicians.

Methods. Through a cross-section study design, a representative sample of the attendants of KAMC, were requested to complete a pre-designed validated questionnaire reflecting their preferences on characteristics of their treating physicians. This study

Disclosure. Authors have no conflict of interests, and the work was not supported or funded by any drug company. was carried out between November 2017 and January 2018 in KAMC. The study population included all Saudi males and females aged above 13 years old (cut off age of independency) attending King Khalid Hospital $(\mathrm{KKH})$, Jeddah, KSA. The illiterate patients were excluded from the study. Using the Epi Info (software package), putting into consideration a confidence level at $95 \%$. As there is no definite outcome for the preferences of the patients, and to achieve maximum sample size, the expected frequency was substituted in the equation by 0.5 , with a margin of error at 0.05 ; the sample size accounted for 384 . A representative sample was selected from the attendants KAMC, through systematic sampling. Every third attendant of the general internal medicine outpatient clinic of $\mathrm{KKH}$ during weekdays of the month of January 2018 who fulfills the inclusion criteria was invited to be involved in the study and respond to the questionnaire.

A well written questionnaire was constructed, translated, and validated by face and content validity method. The reliability of the survey was checked by piloting and Cronbach's alpha test. The Arabic questionnaire was distributed among participants. The participantshad to fill up the questionnaire by themselves. The survey contains personal data (12 variables), personality traits ( 15 variables) that is categorized into 5 major groups (3 questions represent each group) with Likert's scale of 5 options (very accurate, moderately accurate, neutral, moderately inaccurate, and very inaccurate), and the features desired by the participants in their physicians (28 variables) with Likert's scale of 5 options (very important, important, neutral, unimportant, and very unimportant). An example of the personal data we used are the number of clinic visits per year, educational and financial classification of the participant. The personality traits were stated using international personality item pool (IPIP) survey, which is managed by Oregon research institute. ${ }^{13}$ Some of these statements are: "I feel comfortable around people", and "I worry about things". An instance of the statement of the desired features are: "showing an empathetic response", and "devoting enough time for me".

Further categorization of these features to 5 groups for easy analysis and applicability (physician attitude, features of acquiring information phase, features of physical examination and investigations phase, features of condition explanation phase, and features of supporting and treatment options). The questionnaire was distributed to the selected participants at the general internal medicine outpatient clinics in $\mathrm{KKH}$. 
Permission and IRB approval to collect the data was obtained from health authorities and Ethical Committee of the King Abdullah International Medical Research Center, Riyadh KSA. Informed consent of the participants was considered as a prerequisite for inclusion in the study. The collected data was kept confidentially and was not disclosed, except to serve the purposes of the study.

Statistical analysis. The Statistical Package for Social Sciences, version 21 (IBM Corp. Armonk, NY, USA) was used in analyzing the collected data. The results were presented as frequencies and percentages for the qualitative variable, and independent sample t-test, ANOVA, Bonferroni adjustment test and Pearson correlation was used to test the significance of differences in the preferences of the patients for the characteristics of their treating physicians according to their demographic characteristics and personality traits. A $p<0.05$ was considered significant.

Results. The survey was distributed to 388 participants, 366 of them answered the provided questionnaire giving a response rate of $95.3 \%$. Table 1 shows that females constituted slightly more than one half of the respondents $(54.4 \%)$, who were mostly in the age group $20-40$ years $(n=203,55.5 \%)$, and only 3 respondents $(0.8 \%)$ aged more than 65 years. Almost two-thirds of the respondents were highly educated, out of them $44.8 \%$ had a bachelor qualification, and $22 \%$ had postgraduate degrees. Therefore, it was found that the majority $(72 \%)$ had family monthly income equal to 500 USD or more, with $38.5 \%$ who had monthly income ranging between 2500-10000 USD, and $10.7 \%$ who had monthly income more than 10000 USD. Among identified jobs, teachers formed (12.3\%) of the respondents, while engineers constituted $(4.6 \%)$ and physicians (12.8\%). Almost one third of the respondents reported that they had chronic diseases, out of them there were $7.1 \%$ diabetics and $7.1 \%$ hypertensive, while $1.6 \%$ had heart diseases. In this respect, $17.5 \%$ indicated that they had visited medical clinics 5 times in the past 12 months, in addition to $10.1 \%$ who visited it more than 5 times (Table 1 ).

To demonstrate the personality traits of the respondents, Figure 1 shows their responses to items based on their self-perception for how much accurate these items describe aspects of their personality, the highest scores were recorded for both openness and conscientiousness, followed by agreeableness and neuroticism, and the least was extraversion.

Respondent's preferences on their treating physician. To facilitate interpretation of the preferences of the
Table 1 - Characteristics of the respondents $(\mathrm{N}=366)$.

\begin{tabular}{|c|c|}
\hline Characteristics & n (\%) \\
\hline \multicolumn{2}{|l|}{ Gender } \\
\hline Male & $167(45.6)$ \\
\hline Female & $199(54.4)$ \\
\hline \multicolumn{2}{|l|}{ Age groups (years) } \\
\hline 13-19 years & $30 \quad(8.2)$ \\
\hline $20-40$ & $203(55.5)$ \\
\hline $41-65$ & $130(35.5)$ \\
\hline$>65$ & $3(0.8)$ \\
\hline \multicolumn{2}{|l|}{ Education } \\
\hline Intermediate & $17 \quad(4.6)$ \\
\hline Secondary & $65(17.8)$ \\
\hline Diploma & $40(10.9)$ \\
\hline Bachelor & $164(44.8)$ \\
\hline Postgraduate & 80 (21.9) \\
\hline \multicolumn{2}{|c|}{ Family monthly income (US\$) } \\
\hline$<500$ & $103(28.1)$ \\
\hline $500-<2500$ & $83(22.7)$ \\
\hline $2500-10000$ & $141(38.5)$ \\
\hline$>10000$ & $39(10.7)$ \\
\hline \multicolumn{2}{|l|}{ Occupation } \\
\hline Teacher & $45(12.3)$ \\
\hline Engineer & $17 \quad(4.6)$ \\
\hline Physician & $47(12.8)$ \\
\hline Student & $85(23.2)$ \\
\hline Unemployed & $36 \quad(9.8)$ \\
\hline Others & $136(37.2)$ \\
\hline \multicolumn{2}{|l|}{ Chronic diseases } \\
\hline Diabetes & $26(7.1)$ \\
\hline Hypertension & $26(7.1)$ \\
\hline Heart diseases & $6 \quad(1.6)$ \\
\hline Other chronic diseases & $69(18.9)$ \\
\hline Total & $127(34.7)$ \\
\hline \multicolumn{2}{|c|}{ Number of visits to medical clinics in the past 12 months } \\
\hline No visits & $53(14.5)$ \\
\hline 1 visit & $50(13.7)$ \\
\hline 2 visits & $69(18.9)$ \\
\hline 3 visits & $51(13.9)$ \\
\hline 4 visits & $42(11.5)$ \\
\hline 5 visits & $64(17.5)$ \\
\hline$>5$ visits & $37(10.1)$ \\
\hline
\end{tabular}

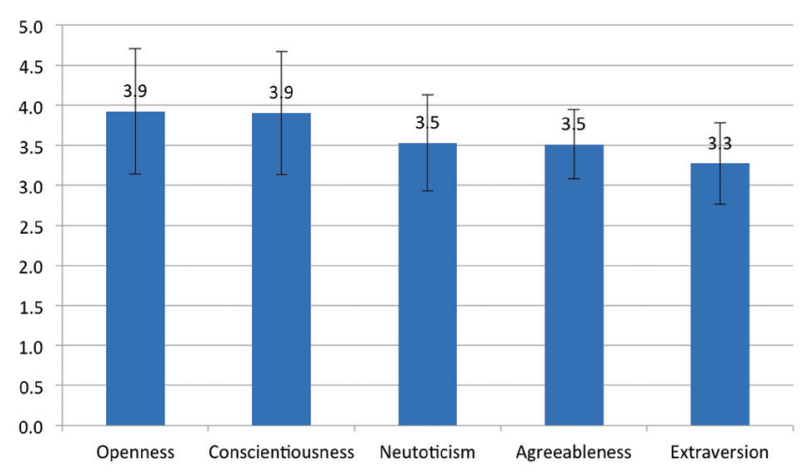

Figure 1 - Average scores of the 5 domains of personality traits of the respondents. 
respondents, their responses to each item was scored with a maximum of 5 for being very important. Table 2 shows that the highest concern for the respondents on their treating physician is being accurate during consultation (4.8 \pm 0.46$)$, showing the results of the tests carried out $(4.8 \pm 0.52)$, paying attention and listening carefully ( $4.8 \pm 0.54)$, explaining the nature of the illness clearly $(4.8 \pm 0.54)$ and examining carefully to know the cause of the condition $(4.8 \pm 0.57)$, on the other hand, the least concern was on nationality of the physician $(2.7 \pm 1.24)$.

Regarding differences in the preferences of the respondents according to their characteristics, Table 3 demonstrates that females are significantly more concerned than males on the importance of paying attention and listening carefully $(4.8 \pm 0.41$ versus [vs] $4.7 \pm 0.66) p<0.05$, the physician should give information without waiting for asking him $(4.4 \pm 0.83$ vs $4.1 \pm 1.01)$ $(p<0.05)$ and examining the patients carefully to find out the cause of the condition $(4.8 \pm 0.47$ vs $4.7 \pm 0.67)$, $(p<0.05)$.

Table 3 shows that older respondents are significantly more interested in that the treating physician should devote enough time to talk on the patients' condition freely $(4.8 \pm 0.40)$, being interested in the patients' personal situation $(4.7 \pm 0.60)$, maintaining eye contact $(4.5 \pm 0.82)$, interested in what the patients want to be carried out $(4.5 \pm 0.73)$, finding out how serious is the problem $(4.8 \pm 0.46)$, gives information without waiting

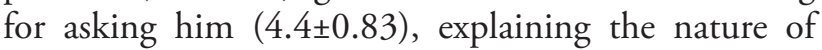

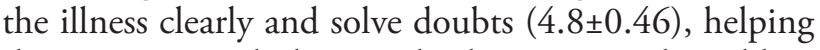
the patient in dealing with the emotional problem related to the health status $(4.3 \pm 0.87)$, providing symptomatic relief $(4.7 \pm 0.54)$ and telling how long the illness would last and the number of expected follow ups $(4.8 \pm 0.48)(p<0.05)$. Regarding monthly income, it shows that respondents with higher monthly income are significantly more concerned in that the treating physician being interested in their personal situation, maintain eye contact when talking to them, interested in what they want to be carried out, finding out how serious is their problems and explaining the nature of their illness and solving any doubts $(p<0.05)$. On education level, respondents with higher education levels are significantly more concerned in that the treating

Table 2 - Mean scores for the rating of the respondents about the importance of the items describing their preferences in their treating physicians.

\begin{tabular}{|c|c|}
\hline Preference statements & Mean \pm SD \\
\hline Being accurate during consultation & $4.8 \pm 0.46$ \\
\hline Showing the results of the tests that have been completed & $4.8 \pm 0.52$ \\
\hline Paying attention and listening to me carefully & $4.8 \pm 0.54$ \\
\hline Explaining the nature of my illness clearly and resolving my doubts & $4.8 \pm 0.54$ \\
\hline Examining me for the cause of my condition & $4.8 \pm 0.57$ \\
\hline Explaining the likely course of my problem & $4.7 \pm 0.57$ \\
\hline Devoting sufficient time for me to talk about my condition freely & $4.7 \pm 0.55$ \\
\hline Explaining what my symptoms mean & $4.7 \pm 0.56$ \\
\hline Determining the seriousness of my problem & $4.7 \pm 0.57$ \\
\hline Explaining the reason for treatment & $4.7 \pm 0.62$ \\
\hline Discussing all available treatment options; agreeing on treatment or letting the patient make the final decision & $4.6 \pm 0.59$ \\
\hline Providing symptomatic relief & $4.6 \pm 0.61$ \\
\hline Explaining how long the illness will last and the number of follow ups & $4.6 \pm 0.65$ \\
\hline Prescribing minimum possible medications & $4.6 \pm 0.68$ \\
\hline Giving a realistic but optimistic picture of my future health & $4.6 \pm 0.69$ \\
\hline Being interested in me and my personal situation & $4.6 \pm 0.76$ \\
\hline Showing me that he/she understands me very well & $4.5 \pm 0.71$ \\
\hline Being friendly (smiling, listening, and caring) and approachable while treating the patient & $4.5 \pm 0.73$ \\
\hline Giving supporting words during my conversation, such as okay, yes, I see, right & $4.4 \pm 0.86$ \\
\hline Administering more tests to reassure me & $4.4 \pm 0.89$ \\
\hline Being interested in what I want done & $4.4 \pm 0.82$ \\
\hline Maintaining eye contact when we are talking & $4.3 \pm 0.88$ \\
\hline Offering information without waiting for me to ask & $4.3 \pm 0.92$ \\
\hline Helping me deal with emotional problems related to my health status & $4.2 \pm 0.93$ \\
\hline Having good knowledge in diagnosing and treating, regardless of the way I am treated & $4.2 \pm 1.05$ \\
\hline Showing an empathetic response & $4.1 \pm 0.98$ \\
\hline Not being overly friendly & $3.8 \pm 1.10$ \\
\hline Being of my nationality & $2.7 \pm 1.24$ \\
\hline
\end{tabular}


physician explain the nature of their illness clearly and solving any doubts, they are significantly less caring on the physician having a good knowledge in diagnosis and treatment $(p<0.05)$. Table 3 also shows that respondents who are suffering from chronic diseases are significantly more concerned in that the treating physician is interested in them and their personal situation, being friendly and approachable while treating them, showing empathetic response, showing that he is understanding them very well, finding out how serious is their problem and explains the nature of their illness clearly and solves any doubt $(p<0.05)$.

Moreover, respecting the association between preferences of the respondents for their treating physician and domains of personality traits. Table 4 show that there are significant positive association between "openness" and preferences of the physician having the same nationality, not being too much friendly, devoting enough time to talk about patient's condition freely, showing interest, paying attention and listening carefully, maintaining eye contact, giving supporting words, showing empathetic response, showing that he understands very well, doing more tests for reassurance, dealing with emotional problems, explaining the reason of treatment and prescribing minimum possible medications.

Also, there are significant positive association between extraversion and preferences of the physician have good knowledge in diagnosis and treatment, maintain eye contact, showing interest on what they want, doing more tests to reassure patients, help in dealing with emotional problems and prescribing minimum possible medications.

There are also significant positive association between agreeableness and preferences of the physician devoting

Table 3 - Differences in the preferences of respondents in their treating physicians according to their gender, age, income, education, and health status.

\begin{tabular}{|c|c|c|c|c|c|}
\hline Preference statements & Gender & Age & Monthly income & Educational level & Chronic diseases \\
\hline Being of my nationality & 0.433 & 0.224 & 0.777 & 0.386 & 0.256 \\
\hline Not being overly friendly & 0.435 & 0.519 & 0.130 & 0.148 & 0.635 \\
\hline $\begin{array}{l}\text { Having good knowledge in diagnosing and treating regardless of the way } \\
\text { I am treated }\end{array}$ & 0.343 & 0.199 & 0.594 & $0.022^{*}$ & 0.483 \\
\hline Devoting enough time for me to freely talk about my condition & 0.263 & $0.010^{*}$ & 0.301 & 0.189 & 0.100 \\
\hline Being interested in me and my personal situation & 0.532 & $0.008^{*}$ & $0.013^{*}$ & 0.560 & 0.019 \\
\hline Being accurate during consultation & 0.213 & 0.279 & 0.785 & 0.512 & 0.739 \\
\hline Paying attention and listening to me carefully & $0.007^{*}$ & 0.821 & 0.955 & 0.795 & 0.150 \\
\hline Maintaining eye contact when we are talking & 0.410 & $0.008^{*}$ & $0.006^{*}$ & 0.181 & 0.171 \\
\hline Being interested in what I want done & 0.285 & $0.013^{*}$ & $0.022^{*}$ & 0.112 & 0.155 \\
\hline $\begin{array}{l}\text { Being friendly (smiling, listening, and caring) and approachable when } \\
\text { treating the patient }\end{array}$ & 0.499 & 0.444 & 0.489 & 0.268 & 0.031 \\
\hline $\begin{array}{l}\text { Giving supporting words during my conversation, such as okay, yes, } \\
\text { I see, right }\end{array}$ & 0.119 & 0.800 & 0.318 & 0.242 & 0.305 \\
\hline Showing an empathetic response & 0.065 & 0.283 & 0.090 & 0.505 & $0.020^{*}$ \\
\hline Showing me that he/she is understanding me very well & 0.778 & 0.481 & 0.855 & 0.554 & $0.020^{*}$ \\
\hline Determining the seriousness of my problem & 0.330 & $0.019^{*}$ & $0.042^{*}$ & 0.761 & $0.010^{*}$ \\
\hline Offering information without waiting for me to ask & $0.005^{*}$ & 0.043 & $0.051^{*}$ & 0.144 & 0.729 \\
\hline Explaining the nature of my illness clearly and resolving my doubts & 0.137 & $0.002^{*}$ & $0.011^{*}$ & $0.019^{*}$ & $0.025^{*}$ \\
\hline Explaining what my symptoms mean & 0.061 & 0.363 & 0.320 & 0.341 & 0.310 \\
\hline Explaining the likely course of my problem & 0.056 & 0.088 & 0.752 & 0.629 & 0.220 \\
\hline Examining me for the cause of my condition & $0.007^{*}$ & 0.124 & 0.505 & 0.417 & 0.438 \\
\hline Administering more tests to reassure me & 0.559 & 0.078 & 0.519 & 0.413 & 0.081 \\
\hline Showing me the results of the completed tests & 0.208 & 0.090 & 0.539 & 0.244 & 0.595 \\
\hline Giving a realistic but optimistic picture of my future health & 0.057 & 0.136 & 0.056 & 0.111 & 0.534 \\
\hline Helping me deal with emotional problems related to my health status & 0.514 & $0.010^{*}$ & 0.148 & 0.116 & 0.356 \\
\hline $\begin{array}{l}\text { Discussing all available treatment options; agreeing on treatment or letting } \\
\text { the patient make the final decision }\end{array}$ & 0.103 & 0.152 & 0.449 & 0.110 & 0.362 \\
\hline Explaining the reason for treatment & 0.212 & 0.154 & 0.322 & 0.549 & 0.360 \\
\hline Prescribing minimum possible medications & 0.682 & 0.283 & 0.854 & 0.822 & 0.283 \\
\hline Providing symptomatic relief & 0.241 & $0.005^{*}$ & 0.201 & 0.177 & 0.234 \\
\hline Explaining how long the illness will last and the number of follow ups & 0.066 & $0.046^{*}$ & 0.236 & 0.061 & 0.163 \\
\hline
\end{tabular}

*Values with significant $p$-value $(<0.05)$. Based on independent sample t-test (gender, chronic diseases), based on ANOVA t-test (age, monthly income, educational level), results adjusted by Bonferroni test 
Table 4 - Correlation between preferences of respondents in their treating physicians and their main domains of personality traits.

\begin{tabular}{|c|c|c|c|c|c|}
\hline \multirow[t]{2}{*}{ Preferences' statements } & \multicolumn{5}{|c|}{ Domains of the personality traits } \\
\hline & Openness & Extraversion & Agreeableness & Conscientiousness & Neuroticism \\
\hline Being from my nationality & $0.131^{*}$ & 0.103 & 0.06 & $0.198^{\dagger}$ & 0.06 \\
\hline Not being too much friendly & $0.145^{*}$ & 0.07 & 0.01 & $0.118^{*}$ & 0.001 \\
\hline $\begin{array}{l}\text { Having a good knowledge in diagnosing and treating regardless by } \\
\text { which way he/she treat me }\end{array}$ & 0.094 & $0.128^{*}$ & 0.013 & $0.168^{\dagger}$ & 0.03 \\
\hline Devoting enough time for me to talk about my condition freely & $0.153^{*}$ & 0.069 & $0.117^{*}$ & $0.126^{*}$ & 0.086 \\
\hline Being interested to me and my personal situation & $0.201^{\dagger}$ & 0.101 & $0.148^{*}$ & $0.181^{\dagger}$ & $0.119^{*}$ \\
\hline Being accurate during consultation & 0.086 & 0.087 & 0.109 & $0.170^{\dagger}$ & 0.039 \\
\hline Paying attention and listening to me carefully & $0.135^{*}$ & 0.075 & $0.145^{*}$ & 0.097 & 0.097 \\
\hline Maintaining eye contact when either he/she or I are talking & $0.219^{\dagger}$ & $0.182^{\dagger}$ & $0.193^{\dagger}$ & $0.208^{\dagger}$ & 0.041 \\
\hline Being interested in what I want done & 0.105 & $0.123^{*}$ & 0.071 & $0.128^{*}$ & 0.026 \\
\hline $\begin{array}{l}\text { Being friendly (smile, listen, and care) and approachable while } \\
\text { treating the patient }\end{array}$ & $0.125^{*}$ & 0.043 & 0.079 & 0.088 & 0.107 \\
\hline Giving supporting words during my speech such as (ok, yeah, right) & $0.134^{*}$ & 0.018 & 0.093 & 0.07 & 0.08 \\
\hline Showing an empathetic response & $0.124^{*}$ & 0.109 & 0.105 & $0.162^{\dagger}$ & 0.035 \\
\hline Showing me that he is understanding me very well & $0.189^{\dagger}$ & 0.025 & 0.081 & 0.064 & $0.174^{\dagger}$ \\
\hline Finding out how serious my problem is & 0.111 & 0.052 & 0.108 & 0.033 & 0.094 \\
\hline Giving information without waiting me to ask & 0.09 & 0.089 & 0.056 & $0.135^{*}$ & 0.095 \\
\hline Explaining the nature of my illness clearly and solving my doubts & 0.105 & 0.027 & $0.153^{\dagger}$ & 0.034 & $0.118^{*}$ \\
\hline Telling me what my symptoms means & 0.00 & 0.041 & 0.061 & 0.081 & 0.08 \\
\hline Explaining the likely course of my problem & 0.018 & 0.058 & 0.02 & 0.025 & 0.076 \\
\hline Explaining me for the cause of my condition & 0.035 & 0.060 & 0.047 & 0.004 & 0.009 \\
\hline Doing more tests to reassure me & $0.166^{\dagger}$ & $0.160^{\dagger}$ & 0.037 & $0.153^{*}$ & 0.079 \\
\hline Showing me the results of the tests that have been done & $0.150^{*}$ & 0.1 & $0.169^{\dagger}$ & 0.114 & $0.132^{*}$ \\
\hline Giving a realistic but optimistic picture of my future health & 0.062 & $0.117^{*}$ & $0.168^{\dagger}$ & 0.058 & 0.031 \\
\hline $\begin{array}{l}\text { Helping me in dealing with emotional problems related to my health } \\
\text { status }\end{array}$ & $0.176^{\dagger}$ & $0.130^{*}$ & 0.083 & $0.194^{\dagger}$ & 0.087 \\
\hline $\begin{array}{l}\text { Discussing all available treatment options and agree in treatment or } \\
\text { letting the patient make the final decision }\end{array}$ & 0.047 & 0.047 & 0.092 & 0.081 & 0.054 \\
\hline Explaining the reason of treatment & $0.127^{*}$ & 0.054 & 0.108 & 0.026 & 0.026 \\
\hline Prescribing minimum possible medications & $0.132^{*}$ & $0.135^{*}$ & 0.101 & 0.043 & 0.088 \\
\hline Providing symptomatic relief & 0.092 & 0.015 & 0.075 & 0.068 & $0.125^{*}$ \\
\hline Telling me how long the illness will last and the number of follow ups & 0.079 & 0.045 & 0.051 & 0.068 & 0.031 \\
\hline
\end{tabular}

Based on Pearson correlation (r). * significant at $p<0.05,{ }^{\dagger}$ significant at $p<0.001$

enough time to talk regarding patients' condition freely, showing interest in patients' personal situation, paying attention and listening carefully, maintaining eye contact, explaining the nature of the illness, showing the results of the tests, and giving a realistic but optimistic picture of future health.

There are also significant positive association between conscientiousness and preferences of the physician having the same nationality, not being too much friendly, have good knowledge in diagnosis and treatment, devoting enough time to talk on patient' condition freely, showing interest in patient' personal situation, being accurate during consultation, paying attention and listening carefully, maintaining eye contact, showing interest on what they want, showing empathetic response, give information without waiting for asking, doing more tests to reassure the patient and dealing with the emotional problems related to their health status.

Finally, there are significant positive association between neuroticism and preferences of the physician being interested in the personal situation, showing that he understand very well, explaining the nature of the illness and solving doubts, showing results of the tests and provides symptomatic relief (Table 4).

Discussion. The effectiveness of the health care services is influenced by the interaction between the patients and their treating physicians. The physicians who are aware on their patient expectations are more productive in their clinical negotiations. ${ }^{14}$ The current study aims to explore the preferences of systematically selected individuals on their treating physicians and finding out potential predictors influencing their preferences. 
In a systematic review carried out by Jung et $\mathrm{al},{ }^{15}$ reviewed 145 published articles investigating the patients' characteristics as predictors for their primary health care preferences along 3 decades from 1974 to 2001. In their study, they focused on certain characteristics such as age, gender, educational level, and marital status. Regarding age, they emphasized what was documented by Al-Bashir, ${ }^{16}$ who found that older patients often give greater concern on physician being kind and attentive, which support our findings where older respondents showed concern on devoting enough time for talking, maintain eye contact, look after what they want to be carried out, and care on their emotional state related to their disease based on their personal situation. Also, Lefèvre et al, ${ }^{17}$ revealed interest of older patients regarding information related to their care and understanding of medication, which accords our findings where older respondents expressed that they expect that the treating physician give information without asking for it and explaining the nature of the illness clearly and solve doubts. Moreover, older patients were found to be more curious on time; in our study, older respondents were more concerned on how long the illness would last and the number of expected visits. ${ }^{18}$

Female patients has some distinct features to prefer a physician. As Rigby et $\mathrm{al}^{19}{ }^{19}$ expressed that female patients have greater preference for information and understanding medications, in this line, our female respondents showed significantly higher interests than males regarding the necessity of the physician paying attention and listening carefully, and give information without waiting for questions. Generally, females are seeking for attention behaviors toward their medical situation form their treating physicians. ${ }^{20}$

Say et $\mathrm{al},{ }^{21}$ reported that educated patients and women being quite consistently prefer a more active role in decision making; that could explain our findings which showed that respondents with higher education levels are significantly more concerned in that the treating physician explains to them the nature of their illness clearly and solving any doubts regardless of having a good knowledge in diagnosis and treatment.

Economic status was found to modify the preferences of the patients in the expected health care, for example Fried et $\mathrm{al}^{22}$ concluded that patients with higher economic status give greater preference to diagnosis and treatment of illness and correct use of technology. In the current study, the participants with higher monthly income denoted that they are concerned with finding out how serious is their problems, explaining the nature of their illness, and solving any doubts. Also, individuals with higher economic status are more likely to have a higher self-esteem; therefore, they prefer patient-centered care. $^{23}$ That was remarked in our study, where respondents with higher economic status expressed more importance regarding physician being interested in their personal situation, maintain eye contact when talking to them, and interested in what they want to be carried out.

Patients with poor health are often seeking for personal attention. ${ }^{16}$ Similarly, our findings showed that respondents who reported chronic diseases were more concerned to have a physician who is interested in their personal situation, being friendly and approachable while treating them, showing empathetic response and understanding them very well. Unfortunately, as Levinston et al, ${ }^{24}$ stated that between $57 \%$ to $75 \%$ of the doctor's expressions in general practice can be characterized as task-oriented and only a small part of it was devoted to psychosocial exchanges. Moreover, as emphasized by Shin et al, ${ }^{25}$ patients with poor health are interested in being told the truth regarding diagnosis and prognosis of their condition. The respondents with chronic diseases in our study showed their interest in finding out how serious was their problem, explained the nature of their illness clearly, and solved any doubts.

Despite of its importance, little attention has been given to the main personality dimensions of the patients as possible predictors for health behaviors; which, gives importance to the findings of the current study. It revealed that each dimension of the personality trait was associated with different package of items reflecting their preferences in their treating physician. ${ }^{26}$ In this respect, according to the findings of Flynn et $\mathrm{al},{ }^{27}$ stated that the increased conscientiousness and openness to experience, decreased agreeableness, and neuroticism corresponded to preferring the most active decision-making style compared with the least active. Therefore, they recommended that a better understanding of how personality traits relate to patient decision-making styles may help clinicians tailor treatment discussions to the needs and preferences of individual patients.

Study limitations. First, this study is directed to patients visiting $\mathrm{KKH}, \mathrm{KSA}$, which is mainly eligible for national guard employees, means that many patients are militaries or relatives of military members. This may play a role in the preferred features of the physician. Secondly, the study is limited to a specific clinic which might not be applicable to generalize the results of this study to different kind of patients who are visiting different clinics.

In conclusion, general internal medicine patients' preferences in their treating physician and the 
expected mode of physician-patient communication are significantly influenced by their demographic characteristics example: age, gender, education level, economic status, and whether they are suffering from chronic diseases. Also, their preferences differ significantly according to their dimensions of personality traits (openness, extraversion, agreeability, conscientiousness and neuroticism).

Despite some differences between each personality domain, they shared some similar features in their treating physician. It is highly recommended, generally, for the treating physician when dealing with any personality to devote time to talk on patients' condition freely, paying attention and listening carefully, maintaining eye contact, and showing interest and empathy during the conversation when interviewing adult middle-aged patient. Also, he should consider other important preferable features for each personality.

\section{References}

1. Ridd M, Shaw A, Lewis G, Salisbury C. The patient-doctor relationship: a synthesis of the qualitative literature on patients' perspectives. Br J Gen Pract 2009; 59: e116-e133.

2. Brédart A, Bouleuc C, Dolbeault S. Doctor-patient communication and satisfaction with care in oncology. Curr Opin Oncol 2005; 17: 351-354.

3. Herndon JH, Pollick KJ. Continuing concerns, new challenges, and next steps in physician-patient communication. J Bone Joint Surg Am 2002; 84: 309-315.

4. Merriel SW, Salisbury C, Metcalfe C, Ridd M. Depth of the patient-doctor relationship and content of general practice consultations: cross-sectional study. Br J Gen Pract 2015; 65: e545-e551.

5. Cooper LA, Roter DL, Johnson RL, Ford DE, Steinwachs DM, Powe NR. Patient-centered communication, ratings of care, and concordance of patient and physician race. Ann Intern Med 2003; 139: 907-915.

6. Lin W, Huang IC, Wang SL, Yang MC, Yaung CL. Continuity of diabetes care is associated with avoidable hospitalizations: evidence from Taiwan's national health insurance scheme. Int J Qual Health Care 2010; 22: 3-8.

7. Uijen AA, Bischoff EW, Schellevis FG, Bor HH, van den Bosch WJ, Schers HJ. Continuity in different care modes and its relationship to quality of life: a randomised controlled trial in patients with COPD. Br J Gen Pract 2012; 62: e422-e428.

8. Worrall G, Knight J. Continuity of care is good for elderly people with diabetes: retrospective cohort study of mortality and hospitalization. Can Fam Physician 2011; 57: e16-e20.

9. Adler R, Vasiliadis A, Bickell N. The relationship between continuity and patient satisfaction: a systematic review. Fam Pract 2010; 27: 171-178.

10. Cheng SH, Chen CC. Effects of continuity of care on medication duplication among the elderly. Med Care 2014; 52 : 149-156.

11. Chen CC, Chen SH. Better continuity of care reduces costs for diabetic patients. Am J Manag Care 2011; 17: 420-427.
12. Elzubier AG. Doctor-patient communication: a skill needed in Saudi Arabia. J Family Community Med 2002; 9: 51-56.

13. Goldberg RL, Johnson AJ, Eber WH, Hogan R, Ashton CM, Cloninger RC, et al. The international personality item pool and future of public-domain personality measures. $J$ Res Pers 2005; 40: 84-96.

14. Coulehan JL, Block MR. The medical interview: Mastering skills for clinical practice [Internet]. Philadelphia: F.A. Davis Company. [Updated 2006. Accessed 2018 October]. Available from URL: https://www.fadavis.com/product/medicalinterview-skills-clinical-practice-coulehan-block

15. Jung HP, Baerveldt C, Olesen F, Grol R, Wensing M. Patient characteristics as predictors of primary health care preferences: a systematic literature analysis. Health Expect 2003; 6: 160-181.

16. Al-Bashir MM, Armstrong D. Preferences of healthy and ill patients for style of general practitioner care: implications for workload and financial incentives under the new contract. $\mathrm{Br} J$ Gen Pract 1991; 41: 6-8.

17. Lefèvre T, Gagnayre R, Gignon M. Patients with chronic conditions: simulate to educate? Adv Health Sci Educ Theory Pract 2017; 22: 1315-1319.

18. Weyker PD, Webb CA. Establishing a patient centered, outpatient total joint home recovery program within an integrated healthcare system. Pain Manag 2020; 10: 23-41.

19. Rigby D, Vass C, Payne K. Opening the 'black box': An overview of methods to investigate the decision-making process in choice-based surveys. Patient 2020; 13: 31-41.

20. Erdem S, Thompson C. Prioritizing health service innovation investments using public preferences: a discrete choice experiment. BMC Health Serv Res 2014; 14: 360.

21. Say R, Murtagh M, Thomson R. Patients' preference for involvement in medical decision making: a narrative review. Patient Educ Couns 2006; 60: 102-114.

22. Fried TR, Bradley EH, Towle VR, Allore H. Understanding the treatment preferences of seriously ill patients. $N$ Engl J Med 2002; 346: 1061-1066.

23. Robinson JH, Callister LC, Berry JA, Dearing KA. Patientcentered care and adherence: definitions and applications to improve outcomes. J Am Acad Nurse Pract 2008; 20: 600-607.

24. Levinson W, Kao A, Kuby A, Thisted RA. Not all patients want to participate in decision making. A national study of public preferences. J Gen Intern Med 2005; 20: 531-535.

25. Shin DW, Cho J, Kim SY, Chung IJ, Kim SS, Yang HK, et al. Discordance among patient preferences, caregiver preferences, and caregiver predictions of patient preferences regarding disclosure of terminal status and end-of-life choices. Psychooncology 2015; 24: 212-219.

26. Hilliard RC, Brewer BW, Cornelius AE, Van Raalte JL. Big five personality characteristics and adherence to clinic-based rehabilitation activities after ACL surgery: A prospective analysis. Open Rehabil J 2014; 7: 1-5.

27. Flynn KE, Smith MA. Personality and health care decisionmaking style. J Gerontol B Psychol Sci Soc Sci 2007; 62: P261-P267. 